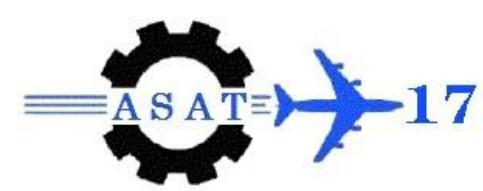

\title{
Solution of Heat Transfer Problem for Thick Walled Automatic Weapon Barrel Subjected to Continuous Firing
}

\author{
$\left\{\text { M. Ghanem*, O. Abdelsalam }{ }^{\dagger}, \text { S. Guirgis }{ }^{\star} \text { and M. S. Aboel Khair }{ }^{\S}\right\}^{* *}$
}

\begin{abstract}
In this paper, analytical solution of time-dependent heat diffusion equation in cylindrical coordinate is derived and solved mathematically for calculating the temperature distribution in thick walled weapon barrel subjected to successive heating and cooling convections and radiations due to continuous firing. The analytical solution has been validated by two numerical models: One is executed by MATLAB to simulate the temperature distribution due to burst fining adopting same assumptions used in analytical model. On other hand, Finite Element model is developed in the environment of ANSYS to solve the problem studying the weight of these assumptions. The results reflect the effect of heat accumulation and the cooling period between two sequential rounds. The temperature-time curves calculated on both inner and outer surfaces of the barrel show good agreement between the analytical and the numerical MATLAB models. However remarkable difference between the F.E.M and the analytical model is presented and discussed.
\end{abstract}

Keywords: Automatic weapons, heat accumulation, thick walled barrels, burst firing, transient thermal.

\section{Nomenclature}

\begin{tabular}{|c|l|c|l|}
\hline $\mathrm{k}$ & Thermal conductivity $[\mathrm{W} / \mathrm{m} \mathrm{k}]$ & $\mathrm{T}$ & Temperature $[\mathrm{k}]$ \\
\hline $\mathrm{C}$ & Specific heat $[\mathrm{J} / \mathrm{kg} \mathrm{k}]$ & $\rho$ & Density $\left[\mathrm{kg} / \mathrm{m}^{3}\right]$ \\
\hline$\alpha$ & Thermal diffusivity $\left[\mathrm{m}^{2} / \mathrm{s}\right]$ & $\dot{\mathrm{q}}$ & Heat generated from barrel \\
\hline $\mathrm{Q}$ & Heat transfer energy $[\mathrm{j}]$ & $\mathrm{t}$ & Time $[\mathrm{s}]$ \\
\hline $\mathrm{h}_{\text {gas }}$ & $\begin{array}{l}\text { Gases convection coefficient }[\mathrm{W} / \\
\left.\mathrm{m}^{2} \mathrm{k}\right]\end{array}$ & $\mathrm{h}_{\infty}$ & $\begin{array}{l}\text { Ambient convection coefficient } \\
{\left[\mathrm{W} / \mathrm{m}^{2} \mathrm{k}\right]}\end{array}$ \\
\hline $\mathrm{T}_{\text {gas }}$ & Gases temperature $[\mathrm{k}]$ & $\mathrm{T}_{\infty}$ & Ambient temperature $[\mathrm{k}]$ \\
\hline$A$ & Area $\left[\mathrm{m}^{2}\right]$ & $\mathrm{r}$ & Radius $[\mathrm{m}]$ \\
\hline $\mathrm{R}_{\mathrm{i}}$ & Inner radius $[\mathrm{m}]$ & $\mathrm{R}_{\mathrm{o}}$ & Outer radius $[\mathrm{m}]$ \\
\hline$\varepsilon$ & Emissivity of the barrel surface & $\sigma$ & Stefan-Boltzmann constant \\
\hline $\mathrm{T}_{\mathrm{O}}$ & Initial temperature of barrel $[\mathrm{k}]$ & $v_{p}$ & Projectile velocity [m/s] \\
\hline$p$ & Pressure of gases [pa] & $\psi$ & Relative burnt mass of propellant \\
\hline$p_{M}$ & Pressure of gases at muzzle $[\mathrm{pa}]$ & $b$ & Exponent of AAPG \\
\hline $\bar{v}$ & Mean velocity of gases $[\mathrm{m} / s]$ & $\bar{\rho}$ & Mean pressure of gases [pa] \\
\hline $\mathrm{Nu}_{\mathrm{D}}$ & Nusselt number & $\mathrm{Ra}_{\mathrm{D}}$ & Rayleigh number \\
\hline
\end{tabular}

\footnotetext{
* m.ghanem@mtc.edu.eg

$\dagger \quad$ ossama.ramy@mtc.edu.eg

* samer.guirgis@mtc.edu.eg

$\S \quad$ m.aboelkhair@mtc.edu.eg

** Egyptian Armed Forces, Egypt.
} 


\begin{tabular}{|c|l|c|l|}
\hline $\mathrm{k}_{\infty}$ & $\begin{array}{l}\text { Ambient thermal conductivity } \\
{[\mathrm{W} / \mathrm{m} \mathrm{k}]}\end{array}$ & $\overline{\mathrm{h}_{\mathrm{g}}}$ & $\begin{array}{l}\text { Average gases convection } \\
\text { coefficient }\left[\mathrm{W} / \mathrm{m}^{2} \mathrm{k}\right]\end{array}$ \\
\hline $\mathrm{D}$ & outer diameter of the barrel $[\mathrm{m}]$ & $C, n$ & Constants which depend on $\mathrm{Ra}_{\mathrm{D}}$ \\
\hline $\mathrm{Y}_{\mathrm{o}}, \mathrm{Y}_{1}$ & $\begin{array}{l}\text { Second type Bessel function of } \\
\text { degree zero and degree one } \\
\text { respectively }\end{array}$ & $\mathrm{J}_{\mathrm{o}}, \mathrm{J}_{1}$ & $\begin{array}{l}\text { First type Bessel function of degree } \\
\text { zero and degree one respectively }\end{array}$ \\
\hline $\mathrm{t}_{\mathrm{EA}}$ & Time of additional action period $[\mathrm{s}]$ & $\overline{\mathrm{T}_{\mathrm{gas}}}$ & Average gases temperature $[\mathrm{k}]$ \\
\hline
\end{tabular}

\section{Introduction}

Barrel bore surface receives large amount of heat resulting from combustion of ammunition propellants and friction between the projectile jacket and the barrel bore. Before another round is fired, the barrel has a very short time to cool down. Nevertheless, there is amount of heat doesn't transfer by means of convection or radiation to the environment that leads to increase of the temperature through the thickness of barrel wall when firing in bursts.

During continuous firing, the gases flow "characterize by high temperature and high pressure" looks like thermal pulses. At the same time, the gun tube is cooled by the air around its outer surface and at the inner surface when the projectile leaves the barrel and before the next round, but combined convection heat transfer coefficient associated with natural cooling is limited. Which leads to heat accumulates and causes the barrel to reach a high temperature which should be limited by the so called "cock-off temperature" which is the temperature at which the cartridge is pre-ignited before complete locking of the breech system due to high temperature. Consequently, the effect of the thermal pulses is rapid heating and cooling to the barrel wall. This phenomenon led to a dramatic change in temperature of the gun barrel wall, [1]. Accordingly, dynamic temperature difference effect is produced, namely, thermal shock.

The inner surface of the barrel lining is a brittle electroplating chromium layer, it is liable to cracks and crack extension under the action of repeated thermal shocks, in turn, and lead to the inner surface of the barrel is destroyed. The research by B. Lawton [2] shows that the thermal effect is the internal cause of the chrome layer cracking, and the process of the projectile engraving in the grooves of the barrel rifle is the external cause of the chrome layer cracking. Repeated thermal effect will make the barrel bore geometry shape change. This may lead to a decrease the muzzle velocity, projectile stability, the firing accuracy and the tactical technical performance of the machine gun declining, [3].

Various mathematical methods are available for solving heat conduction in a composite medium, including Laplace transform method, [4, 5], orthogonal expansion technique[6-8], Green's function approach, [9], line heat-source method, [10, 11] and integral transform technique, [12] ... etc. Recently, rapid advances of computers and software have generated growing interest in solving more general problems in multilayered materials, together with various complexities, for example, involving the one-dimensional [13] or two-dimensional nlayer materials [14], time-dependent boundary conditions [15]. In this paper, the solution of the 1-D diffusion equation with time-dependent boundary conditions is solved analytically using algebra text box, but using some assumptions and the solution is verified using two numerical solutions one with MATLAB toolbox with the same assumptions used in analytic solution and the other with ANSYS with real boundary conditions.

\section{Governing Equations}

The general heat diffusion equation is, [16]: 


$$
\frac{\partial}{\partial \mathrm{x}}\left(\mathrm{k} \frac{\partial \mathrm{T}}{\partial \mathrm{x}}\right)+\frac{\partial}{\partial \mathrm{y}}\left(\mathrm{k} \frac{\partial \mathrm{T}}{\partial \mathrm{y}}\right)+\frac{\partial}{\partial \mathrm{z}}\left(\mathrm{k} \frac{\partial \mathrm{T}}{\partial \mathrm{z}}\right)+\dot{\mathrm{q}}=\mathrm{C} \rho \frac{\partial \mathrm{T}}{\partial \mathrm{t}}
$$

For constant thermal conductivity $(\mathrm{k})$ in three dimensions:

$$
\Rightarrow \frac{\partial^{2} \mathrm{~T}}{\partial \mathrm{x}^{2}}+\frac{\partial^{2} \mathrm{~T}}{\partial \mathrm{y}^{2}}+\frac{\partial^{2} \mathrm{~T}}{\partial \mathrm{z}^{2}}+\frac{\dot{\mathrm{q}}}{\mathrm{k}}=\frac{1}{\alpha} \frac{\partial \mathrm{T}}{\partial \mathrm{t}} \quad, \alpha=\frac{\mathrm{k}}{\mathrm{C} \rho}
$$

The cylindrical coordinates $\mathrm{r}, \varphi$ and $\mathrm{z}$ are used to represent the gun barrel. The gun barrel is centered along the $\mathrm{z}$-axis with the projectile base at $\mathrm{z}=0$ at time $t=0$. Denoting $r=\mathrm{R}_{\mathrm{i}}$ and $r=R_{o}$ as the inner and outer radii of the barrel, respectively, thus the barrel temperature distribution $\mathrm{T}(\mathrm{r}, \varphi, \mathrm{z})$ is represented as follows:

$$
\Rightarrow \frac{\partial^{2} \mathrm{~T}}{\partial \mathrm{r}^{2}}+\frac{1}{\mathrm{r}} \frac{\partial \mathrm{T}}{\partial \mathrm{r}}+\frac{1}{\mathrm{r}^{2}} \frac{\partial^{2} \mathrm{~T}}{\partial \varphi^{2}}+\frac{\partial^{2} \mathrm{~T}}{\partial \mathrm{z}^{2}}+\frac{\dot{\mathrm{q}}}{\mathrm{k}}=\frac{1}{\alpha} \frac{\partial \mathrm{T}}{\partial \mathrm{t}}
$$

According to Newton's law of cooling, [16]

$$
\frac{\partial \mathrm{Q}}{\partial \mathrm{t}}=\mathrm{h}_{\mathrm{gas}} A\left(\mathrm{~T}-\mathrm{T}_{\mathrm{gas}}\right)
$$

From continuity at the boundary, we equate the rate of heat transfer from the gas to the surface with the rate of heat transfer from surface to the barrel volume:

$$
\frac{1}{A} \frac{\partial \mathrm{Q}}{\partial \mathrm{t}}=\mathrm{k} \frac{\partial \mathrm{T}}{\partial \mathrm{r}}
$$

On the inner surface of the barrel, there is convective radiative heat transfer between the gas and the barrel wall. Thus

$$
\mathrm{k}\left|\frac{\partial \mathrm{T}}{\partial \mathrm{r}}\right|_{\mathrm{r}=\mathrm{R}_{\mathrm{i}}}=\mathrm{h}_{\text {gas }}\left(\mathrm{T}-\mathrm{T}_{\text {gas }}\right)+\varepsilon \sigma\left(\mathrm{T}^{4}-\mathrm{T}_{\text {gas }}{ }^{4}\right)
$$

Similarly, the outer surface is represented as cooling is also represented by both convection and radiation:

$$
\mathrm{k}\left|\frac{\partial \mathrm{T}}{\partial \mathrm{r}}\right|_{\mathrm{r}=\mathrm{R}_{\mathrm{o}}}=\mathrm{h}_{\infty}\left(\mathrm{T}_{\infty}-\mathrm{T}\right)+\varepsilon \sigma\left(\mathrm{T}_{\infty}{ }^{4}-\mathrm{T}^{4}\right)
$$

The initial condition at time $t=0$ defines the temperature throughout the barrel to be equal to the ambient temperature for first round:

$$
\mathrm{T}(\mathrm{r}, \mathrm{t})_{\mathrm{t}=0}=\mathrm{T}_{\mathrm{o}}
$$

\subsection{Analytical Model}

To solve the system of differential equations (3), (6), (7), the function of the heat transfer coefficient must be first obtained at each surface $\left(h_{\text {gas }}, h_{\infty}\right)$ and temperatures of the bore gases and of the ambient air $\left(\mathrm{T}_{\text {gas }}, \mathrm{T}_{\infty}\right)$. 


\subsubsection{Internal wall boundary condition}

According to equation (6), the expressions of gases temperature $\left(\mathrm{T}_{\text {gas }}\right)$ and convection coefficient of gases $\left(\mathrm{h}_{\text {gas }}\right)$ are needed to be determined as inputs to solve the differential equations of the system, the internal ballistics solution according to Charbonier Sugot's model is used to determine the different internal ballistics parameters of namely, projectile velocity $\left(v_{p}\right)$, gases pressure $(p)$, gas temperature $\left(\mathrm{T}_{\text {gas }}\right)$ and the percentage of propellant burned $(\psi)$, all as functions of time. However, the interior ballistics calculation ends once the projectile leaves the barrel. After this point, Bravin's law is used to calculate the gases pressure inside the barrel bore as it decays back to the ambient pressure due to discharge of gases:

$$
\mathrm{p}=p_{M} e^{-A t}
$$

Gases temperature $\left(\mathrm{T}_{\text {gas }}\right)$ is assumed to decay exponentially with the same rate as the pressure in this period as in equation (9) and as shown in Fig. 1.

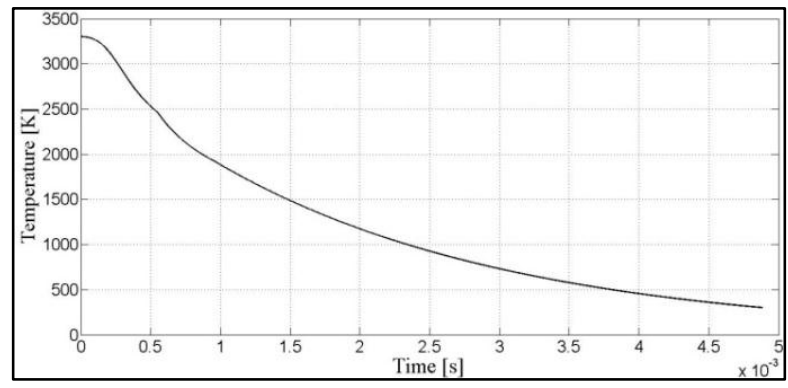

Fig. 1. Temperature of hot gases history

On the other hand, and according to the empirical equation, [17], the convection coefficient of gases $\left(\mathrm{h}_{\text {gas }}\right)$ is determined.

$$
\begin{gathered}
\mathrm{h}_{\text {gas }}=\mathrm{h}_{\infty}+\lambda_{n} \bar{\rho} \mathrm{C}_{p} \bar{v} \\
\lambda_{n}=\left[13.2+4 \log \left(200 \mathrm{R}_{\mathrm{i}}\right)\right]^{-2}
\end{gathered}
$$

In order to estimate mean gases velocity $(\bar{v})$, assume the velocity of gases at the projectile base is equal to the projectile velocity $\left(\bar{v}=v_{p}\right)$, and the velocity of gases at the breech is equal to the breech velocity $\left(\bar{v}=v_{B}=0\right)$, under this assumption the value of mean gases velocity $(\bar{v})$ is expressed as $\left(\bar{v}=0.5 * v_{p}\right)$, mean gases density $(\bar{\rho})$ is calculated by dividing the mass of propellant burnt by the volume from the breech to the projectile base and assumed to decay exponentially after the projectile leaves the barrel as assumed for the temperature, and as shown in Fig. 2.

\subsubsection{External wall boundary condition}

The conditions at the outer wall are very stable in comparison to the inner wall, so the air temperature is held constant at $300[\mathrm{~K}]$. The heat transfer coefficient $\left(\mathrm{h}_{\infty}\right)$ at the outer wall is calculated from the definition of the average Nusselt number $\left(\mathrm{Nu}_{\mathrm{D}}\right)$, around the circumference of the barrel, which is proportional to the Rayleigh number $\left(\mathrm{Ra}_{\mathrm{D}}\right)$, the heat transfer coefficient is calculated as $[18]$ :

$$
\mathrm{h}_{\infty}=\frac{\mathrm{k}_{\infty}}{D} \mathrm{Nu}_{\mathrm{D}}=\frac{\mathrm{k}_{\infty} C}{2 \mathrm{R}_{\mathrm{o}}} \mathrm{Ra}_{\mathrm{D}}{ }^{n}
$$

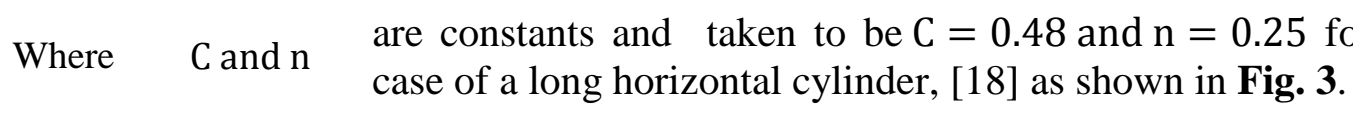




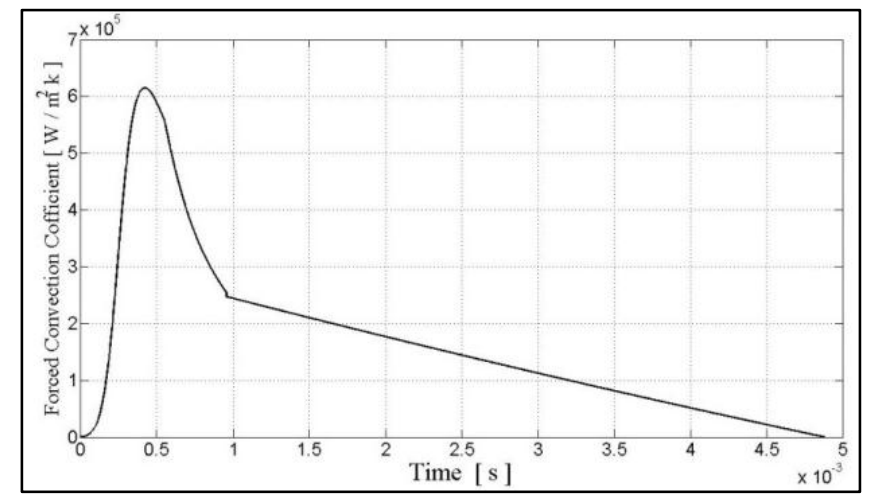

Fig. 2. Convection Coefficient of hot gases

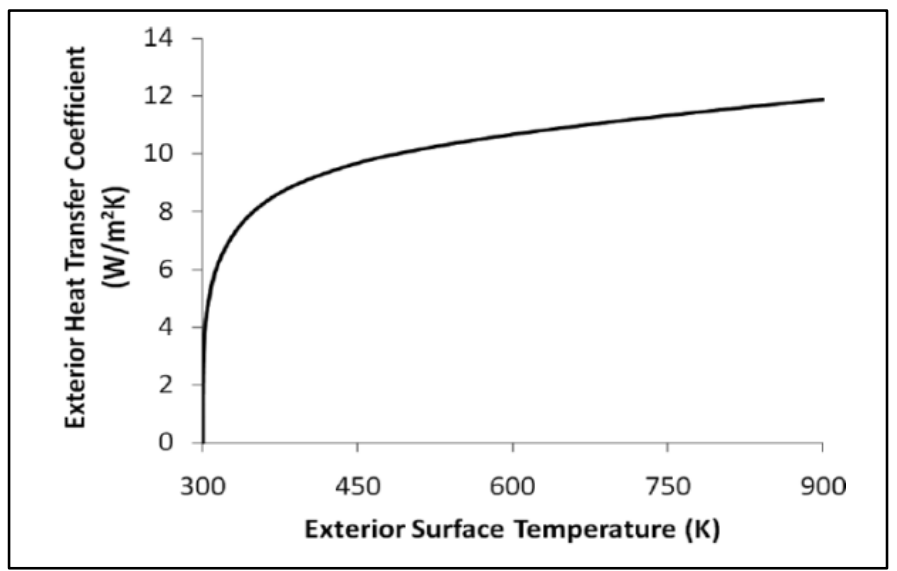

Fig. 3. Ambient convection Coefficient

\subsection{Analytic solution of transient temperature on the barrel thickness}

As the solution of this system is very difficult, the cycle is divide to two stages, first stage ends by end of Additional Action Period of powder Gases (AAPG) "the time between the projectile leaves the barrel and the complete discharge of powder gases", and the second stage ends by end of function cycle of the weapon and just before firing the next round "cooling time at the inner surface of the barrel". To simplify this system the following assumptions have been considered:

- No heat generated from the element.

- One dimension, Heat transferred in radial direction only.

- We neglect the effect of cooling on the outer surface of the barrel, as the process is very rapid and its effect is small.

- The coefficient of convection of gases on first stage is function of time for simplification use average value $\left(\overline{h_{g}}\right)$ "by calculate the area under the curve, as shown in Fig. 4.

- The temperature of gases on first stage is function of time for simplification use average value $\left(\overline{\mathrm{T}_{\text {gas }}}\right)$ "by calculate the area under the curve, as shown in Fig. 5. 


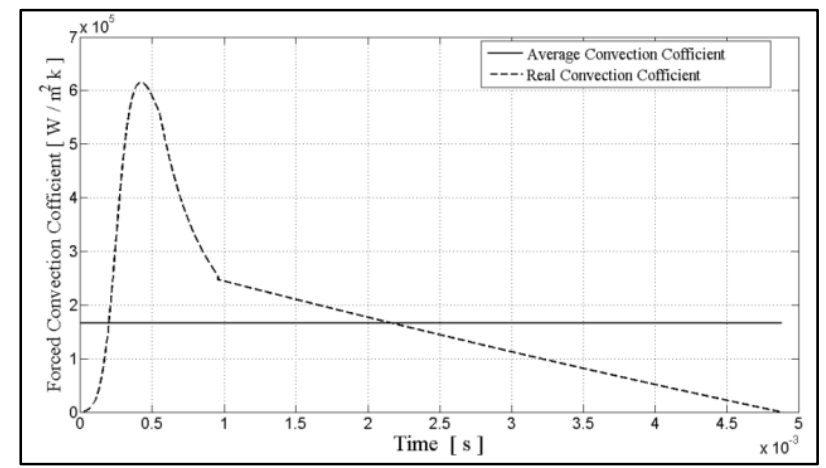

Fig. 4. Real and average convection coefficient of hot gases

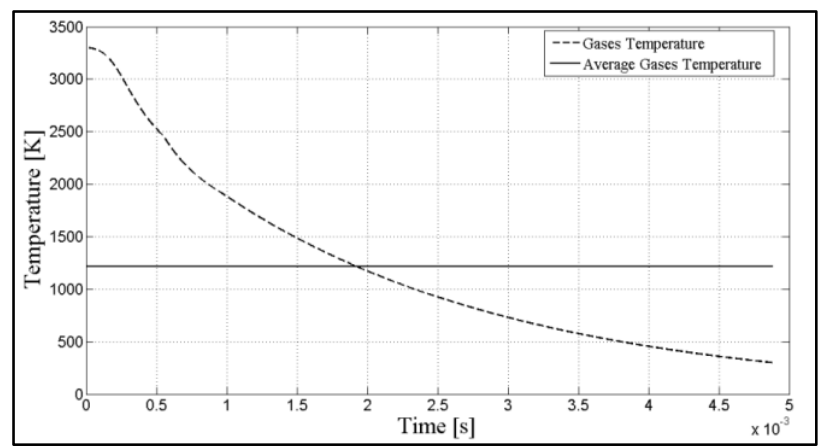

Fig. 5. Real gases temperature and average gases temperature

\subsubsection{Solution of 1st stage}

After using mentioned assumptions the system will be as follows:

$$
\frac{\partial^{2} \mathrm{~T}}{\partial \mathrm{r}^{2}}+\frac{1}{\mathrm{r}} \frac{\partial \mathrm{T}}{\partial \mathrm{r}}=\frac{1}{\alpha} \frac{\partial \mathrm{T}}{\partial \mathrm{t}} \quad, \quad 0 \leq \mathrm{t} \leq \mathrm{t}_{\mathrm{EA}}
$$

The boundary conditions are:

$$
\begin{aligned}
& \mathrm{k}\left|\frac{\partial \mathrm{T}}{\partial \mathrm{r}}\right|_{\mathrm{r}=\mathrm{R}_{\mathrm{i}}}=\overline{\mathrm{h}_{\mathrm{g}}}\left(\mathrm{T}-\overline{\mathrm{T}_{\text {gas }}}\right) \\
& \mathrm{k}\left|\frac{\partial \mathrm{T}}{\partial \mathrm{r}}\right|_{\mathrm{r}=\mathrm{R}_{\mathrm{o}}}=0
\end{aligned}
$$

And the initial condition is: $\quad \mathrm{T}(\mathrm{r}, \mathrm{t})_{\mathrm{t}=0}=\mathrm{T}_{\mathrm{o}}$

$$
\text { Denoting }
$$

$$
\begin{gathered}
\theta=\mathrm{T}-\overline{\mathrm{T}_{\text {gas }}} \\
\frac{\partial^{2} \theta}{\partial \mathrm{r}^{2}}+\frac{1}{\mathrm{r}} \frac{\partial \theta}{\partial \mathrm{r}}=\frac{1}{\alpha} \frac{\partial \theta}{\partial \mathrm{t}}
\end{gathered}
$$

The boundary conditions become:

$$
\begin{aligned}
& \mathrm{k}\left|\frac{\partial \theta}{\partial \mathrm{r}}\right|_{\mathrm{r}=\mathrm{R}_{\mathrm{i}}}=\overline{\mathrm{h}_{\mathrm{g}}} \theta \\
& \mathrm{k}\left|\frac{\partial \theta}{\partial \mathrm{r}}\right|_{\mathrm{r}=\mathrm{R}_{\mathrm{o}}}=0
\end{aligned}
$$

And the initial condition becomes:

$$
\theta(r, t)_{t=0}=T_{o}-\overline{T_{\text {gas }}}
$$


The Partial Differential Equation (PDE) is solved analytically by multiply 2 Ordinary Differential Equations (ODE) one as $f(r)$ and other as $f(t)$. "let $\theta(r, t)=\theta(r) \theta(t) "$

$$
\Rightarrow \frac{\partial \theta}{\partial \mathrm{r}}=\theta(\mathrm{t}) \frac{\mathrm{d} \theta(\mathrm{r})}{\mathrm{dr}}, \frac{\partial^{2} \theta}{\partial \mathrm{r}^{2}}=\theta(\mathrm{t}) \frac{\mathrm{d}^{2} \theta(\mathrm{r})}{\mathrm{dr}^{2}}, \frac{\partial \theta}{\partial \mathrm{t}}=\theta(\mathrm{r}) \frac{\mathrm{d} \theta(\mathrm{t})}{\mathrm{dt}}
$$

Substitute into heat diffusion equation (13):

$$
\Rightarrow \theta(\mathrm{t}) \frac{\mathrm{d}^{2} \theta(\mathrm{r})}{\mathrm{dr}^{2}}+\frac{1}{\mathrm{r}} \theta(\mathrm{t}) \frac{\mathrm{d} \theta(\mathrm{r})}{\mathrm{dr}}=\frac{1}{\alpha} \theta(\mathrm{r}) \frac{\mathrm{d} \theta(\mathrm{t})}{\mathrm{dt}}
$$

By using separation of variables method:

$$
\begin{gathered}
\Rightarrow \frac{1}{\theta(r)}\left(\frac{d^{2} \theta(r)}{d r^{2}}+\frac{1}{r} \frac{d \theta(r)}{d r}\right)=\frac{1}{\alpha \theta(t)} \frac{d \theta(t)}{d t}=-\lambda^{2} \\
\therefore \frac{d^{2} \theta(r)}{d r^{2}}+\frac{1}{r} \frac{d \theta(r)}{d r}+\lambda^{2} \theta(r)=0, \frac{d \theta(t)}{d t}+\alpha \lambda^{2} \theta(t)=0
\end{gathered}
$$

r-Problem:

$$
\begin{gathered}
\because \frac{\mathrm{d}^{2} \theta(\mathrm{r})}{\mathrm{dr}^{2}}+\frac{1}{\mathrm{r}} \frac{\mathrm{d} \theta(\mathrm{r})}{\mathrm{dr}}+\lambda^{2} \theta(\mathrm{r})=0 \\
\Rightarrow \mathrm{r}^{2} \frac{\mathrm{d}^{2} \theta(\mathrm{r})}{\mathrm{dr^{2 }}}+\mathrm{r} \frac{\mathrm{d} \theta(\mathrm{r})}{\mathrm{dr}}+\lambda^{2} \theta(\mathrm{r})=0
\end{gathered}
$$

From Bessel's function, [19]:

$$
\Rightarrow \theta(\mathrm{r})=\mathrm{AJ}_{\mathrm{o}}(\lambda \mathrm{r})+\mathrm{BY}_{\mathrm{o}}(\lambda \mathrm{r})
$$

$\mathrm{t}$ - Problem:

$$
\begin{aligned}
& \frac{\mathrm{d} \theta(\mathrm{t})}{\mathrm{dt}}+\alpha \lambda^{2} \theta(\mathrm{t})=0 \\
\Rightarrow & \theta(\mathrm{t})=\mathrm{Ce}^{-\alpha \lambda^{2} \mathrm{t}}
\end{aligned}
$$

Then the solutions of the differential equations are:

$$
\theta(r, t)=\theta(r) \theta(t)=\left[\mathrm{CJ}_{\mathrm{o}}(\lambda r)+\mathrm{DY}_{\mathrm{o}}(\lambda r)\right] \mathrm{e}^{-\alpha \lambda^{2} \mathrm{t}}
$$

\section{At Boundary Conditions:}

a) $\mathrm{k}\left|\frac{\partial \theta}{\partial \mathrm{r}}\right|_{\mathrm{r}=\mathrm{R}_{\mathrm{i}}}=\mathrm{h}_{\mathrm{g}} \theta$

$$
\left[-\lambda C J_{1}\left(\lambda R_{i}\right)-\lambda D Y_{1}\left(\lambda R_{i}\right)\right] e^{-\alpha \lambda^{2} t}=\frac{\overline{h_{g}}}{k}\left[C_{0}\left(\lambda R_{i}\right)+D Y_{0}\left(\lambda R_{i}\right)\right] e^{-\alpha \lambda^{2} t}
$$




$$
\begin{aligned}
& \therefore\left[-\lambda C \mathrm{~J}_{1}\left(\lambda \mathrm{R}_{\mathrm{i}}\right)-\lambda D \mathrm{Y}_{1}\left(\lambda \mathrm{R}_{\mathrm{i}}\right)\right]=\frac{\overline{\mathrm{h}_{\mathrm{g}}}}{\mathrm{k}}\left[\mathrm{CJ} \mathrm{J}_{0}\left(\lambda \mathrm{R}_{\mathrm{i}}\right)+\mathrm{DY}_{0}\left(\lambda \mathrm{R}_{\mathrm{i}}\right)\right] \\
& \Rightarrow \mathrm{C}\left(\frac{\overline{\mathrm{h}_{\mathrm{g}}}}{\mathrm{k}} \mathrm{J}_{0}\left(\lambda \mathrm{R}_{\mathrm{i}}\right)+\lambda \mathrm{J}_{1}\left(\lambda \mathrm{R}_{\mathrm{i}}\right)\right)+\mathrm{D}\left(\frac{\overline{\mathrm{h}_{\mathrm{g}}}}{\mathrm{k}} \mathrm{Y}_{0}\left(\lambda \mathrm{R}_{\mathrm{i}}\right)+\lambda \mathrm{Y}_{1}\left(\lambda \mathrm{R}_{\mathrm{i}}\right)\right)=0
\end{aligned}
$$

b) $\mathrm{k}\left|\frac{\partial \theta}{\partial \mathrm{r}}\right|_{\mathrm{r}=\mathrm{R}_{\mathrm{o}}}=0$

$$
\begin{aligned}
& {\left[-\lambda C J_{1}\left(\lambda R_{o}\right)-\lambda D Y_{1}\left(\lambda R_{o}\right)\right] e^{-\alpha \lambda^{2} t}=0} \\
& \Rightarrow D=-C \frac{J_{1}\left(\lambda R_{o}\right)}{Y_{1}\left(\lambda R_{o}\right)}
\end{aligned}
$$

Substitute from equation (19) into equation (18):

$$
\begin{gathered}
C\left[\left(\frac{\overline{h_{g}}}{\mathrm{k}} J_{0}\left(\lambda R_{i}\right)+\lambda J_{1}\left(\lambda R_{i}\right)\right)-\frac{J_{1}\left(\lambda R_{o}\right)}{Y_{1}\left(\lambda R_{o}\right)}\left(\frac{\overline{h_{g}}}{\mathrm{k}} Y_{0}\left(\lambda R_{i}\right)+\lambda Y_{1}\left(\lambda R_{i}\right)\right)\right]=0 \\
\Rightarrow C=0 \quad \text { OR } \quad\left[\left(\frac{\overline{h_{g}}}{\mathrm{k}} J_{0}\left(\lambda R_{i}\right)+\lambda J_{1}\left(\lambda R_{i}\right)\right)-\frac{J_{1}\left(\lambda R_{o}\right)}{Y_{1}\left(\lambda R_{o}\right)}\left(\frac{\overline{h_{g}}}{k} Y_{0}\left(\lambda R_{i}\right)+\lambda Y_{1}\left(\lambda R_{i}\right)\right)\right]=0
\end{gathered}
$$

As $\mathrm{C}=0$, Refused as the function diverges at zero [7].

$$
\Rightarrow \operatorname{Res}=\left[\left(\frac{\overline{\mathrm{h}_{\mathrm{g}}}}{\mathrm{k}} \mathrm{J}_{0}\left(\lambda \mathrm{R}_{\mathrm{i}}\right)+\lambda \mathrm{J}_{1}\left(\lambda \mathrm{R}_{\mathrm{i}}\right)\right)-\frac{\mathrm{J}_{1}\left(\lambda \mathrm{R}_{\mathrm{o}}\right)}{\mathrm{Y}_{1}\left(\lambda \mathrm{R}_{\mathrm{o}}\right)}\left(\frac{\overline{\mathrm{h}_{\mathrm{g}}}}{\mathrm{k}} \mathrm{Y}_{0}\left(\lambda \mathrm{R}_{\mathrm{i}}\right)+\lambda \mathrm{Y}_{1}\left(\lambda \mathrm{R}_{\mathrm{i}}\right)\right)\right]=0
$$

The roots of equation (20) are determined numerically as shown in Fig. 6.

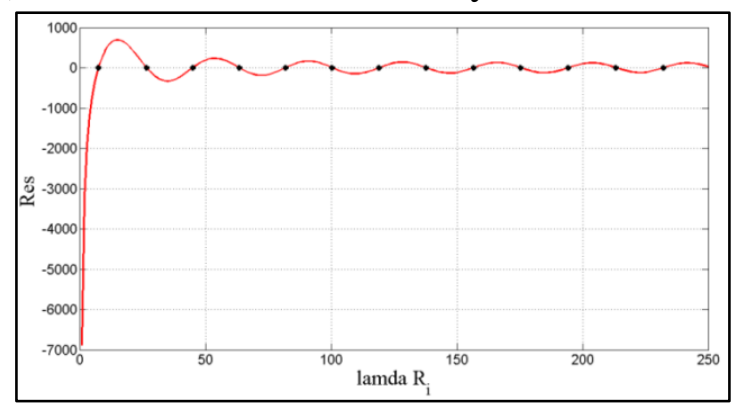

Fig. 6. plot curve for equation (20)

From initial conditions $C_{i}$ at each $\lambda_{i}$ can be determined.

$$
\begin{gathered}
\theta(r, 0)=\mathrm{T}_{\mathrm{o}}-\overline{\mathrm{T}_{\text {gas }}} \quad \& \quad \theta(\mathrm{r}, 0)=\sum_{\mathrm{i}=1}^{\infty} \mathrm{C}_{\mathrm{i}} \mathrm{J}_{\mathrm{o}}\left(\lambda_{\mathrm{i}} \mathrm{r}\right)+\mathrm{D}_{\mathrm{i}} \mathrm{Y}_{\mathrm{o}}\left(\lambda_{\mathrm{i}} \mathrm{r}\right)=\mathrm{T}_{\mathrm{o}}-\overline{\mathrm{T}_{\text {gas }}} \\
\theta(\mathrm{r}, 0)=\sum_{\mathrm{i}=1}^{\infty} \mathrm{C}_{\mathrm{i}}\left(\mathrm{J}_{\mathrm{o}}\left(\lambda_{\mathrm{i}} \mathrm{r}\right)-\frac{\mathrm{J}_{1}\left(\lambda \mathrm{R}_{\mathrm{o}}\right)}{\mathrm{Y}_{1}\left(\lambda \mathrm{R}_{\mathrm{o}}\right)} \mathrm{Y}_{\mathrm{o}}\left(\lambda_{\mathrm{i}} \mathrm{r}\right)\right)=\mathrm{T}_{\mathrm{o}}-\overline{\mathrm{T}_{\text {gas }}}
\end{gathered}
$$


Bessel functions are orthogonal when they are multiplied by the weighting function " $r$ ". Therefore, each side of the above equation is multiplied by the product of the $\mathrm{i}^{\mathrm{th}}$ Eigen function and " $r$ " and then integrated between the two homogenous boundaries, from $r=R_{i}$ to $r=R_{o}$. As usual, only thei ${ }^{\text {th }}$ term in the series remains:

$$
\begin{aligned}
& C_{i} \int_{R_{i}}^{R_{o}}\left(J_{o}\left(\lambda_{i} r\right)-\frac{J_{1}\left(\lambda_{i} r_{\text {out }}\right)}{Y_{1}\left(\lambda_{i} r_{\text {out }}\right)} Y_{o}\left(\lambda_{i} r\right)\right)^{2} r d r=\left(T_{o}-T_{\text {gas }}\right) \int_{R_{i}}^{R_{o}}\left(J_{o}\left(\lambda_{i} r\right)-\frac{J_{1}\left(\lambda_{i} r_{\text {out }}\right)}{Y_{1}\left(\lambda_{i} r_{\text {out }}\right)} Y_{o}\left(\lambda_{i} r\right)\right) r d r \\
& C_{i}=\left(T_{o}-\overline{T_{\text {gas }}}\right) \frac{\int_{R_{i}}^{R_{0}}\left(J_{o}\left(\lambda_{i} r\right)-\frac{J_{1}\left(\lambda_{i} r_{\text {out }}\right)}{Y_{1}\left(\lambda_{i} r_{\text {out }}\right)} Y_{o}\left(\lambda_{i} r\right)\right) r d r}{\int_{R_{i}}^{R_{o}}\left(J_{o}\left(\lambda_{i} r\right)-\frac{J_{1}\left(\lambda_{i} r_{\text {out }}\right)}{Y_{1}\left(\lambda_{i} r_{\text {out }}\right)} Y_{o}\left(\lambda_{i} r\right)\right)^{2} r d r} \quad \Rightarrow C_{i}=\left(T_{o}-\overline{T_{\text {gas }}}\right) \frac{I_{1}}{I_{2}}
\end{aligned}
$$

Using MATLAB toolbox to get $\mathrm{C}_{\mathrm{i}}$ and solve first stage, after solution the temperature time curve on the inner surface on this stage are as shown in Fig. 7.

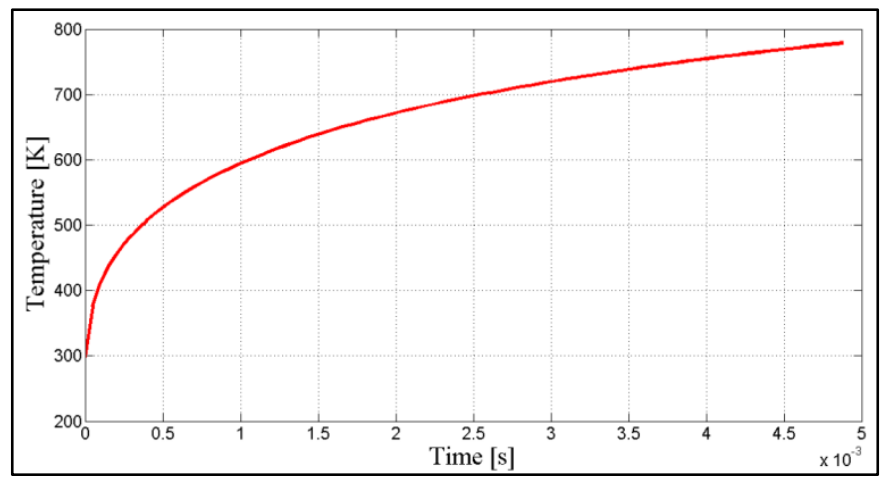

Fig. 7. Temperature Time curve for first stage at inner surface of barrel

\subsubsection{Solution of second stage:}

Solution of this stage looks like the solution mentioned in section (2.2.1) but by assuming

$$
\theta=\mathrm{T}-\mathrm{T}_{\infty}
$$

The solution of this stage is shown in Fig. 8.

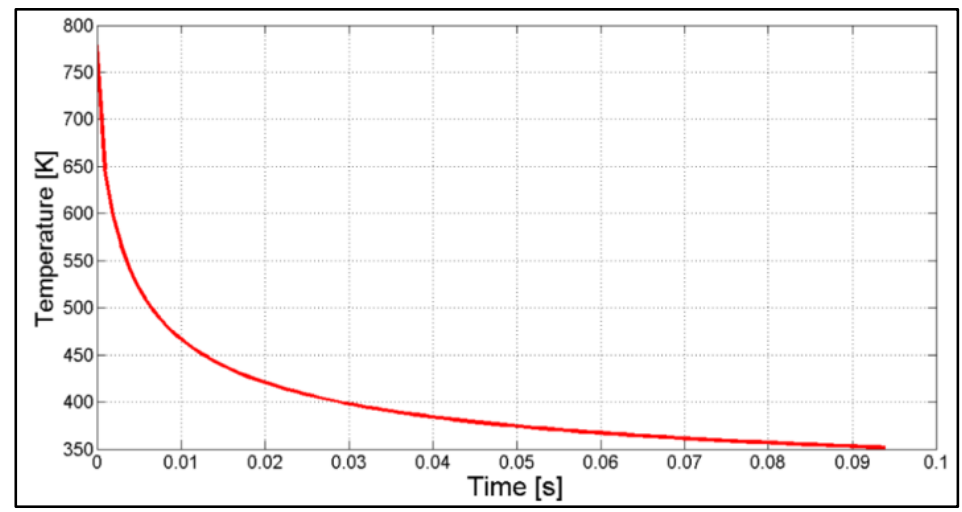

Fig. 8. Temperature time curve for second stage at inner surface of barrel

The solution of first round is shown in Fig. 9, 


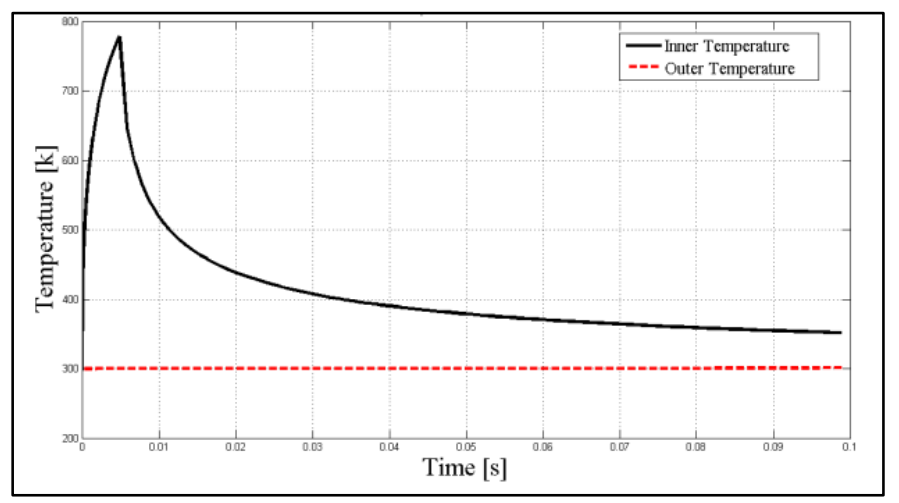

Fig. 9. Temperature time curve for first round at inner surface of barrel

\section{Numerical solution of transient temperature distribution through the barrel thickness}

\subsection{Using MATLAB}

The solution of differential equations (13), (14), Error! Reference source not found., Error! Reference source not found. is performed via MATLAB built-in numerical differential equation solver, pdepe for solving initial-boundary value problem of one dimensional parabolic PDEs. This solver allows many user-options such as the desired precision, time step size...., etc.

pdepe toolbox adopts random time step during calculations. To increase precision calculations between rounds, the maximum step size is set to be 0.001 millisecond. The thickness of the barrel wall is divided into 25 equi-spaced points.

The time interval of the function cycle which is 100 milliseconds is divided into two stages where there a different time step is adopted in each stage. The first stage period is the first 5 milliseconds of the cycle ended by the end of additional action period where the convection coefficient varies rapidly; and the second stage for the remaining 95 milliseconds where the conditions is much calm. So, the solver default time step size is sufficient to optimize computational time.

MATLAB toolbox "pdepe" used to calculate inner temperature and outer temperature at inner layer and outer layer respectively for successive 10 rounds, and compared with analytic solution by maximum difference between two solutions is less than $6 \%$ with respect to analytical solution at point of end of function cycle as shown in Fig. 10 and Fig. 11.

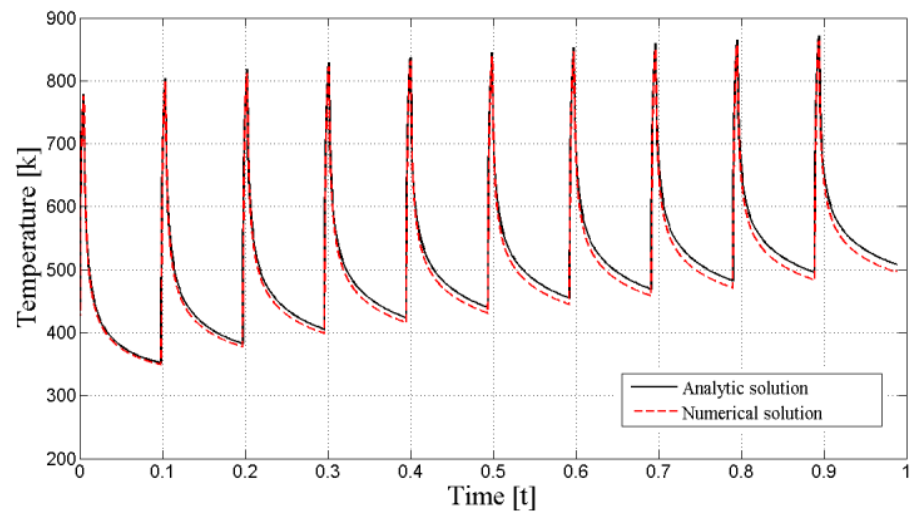

Fig. 10. Temperature time curve for 10 rounds at inner surface for analytical solution and numerical solution 


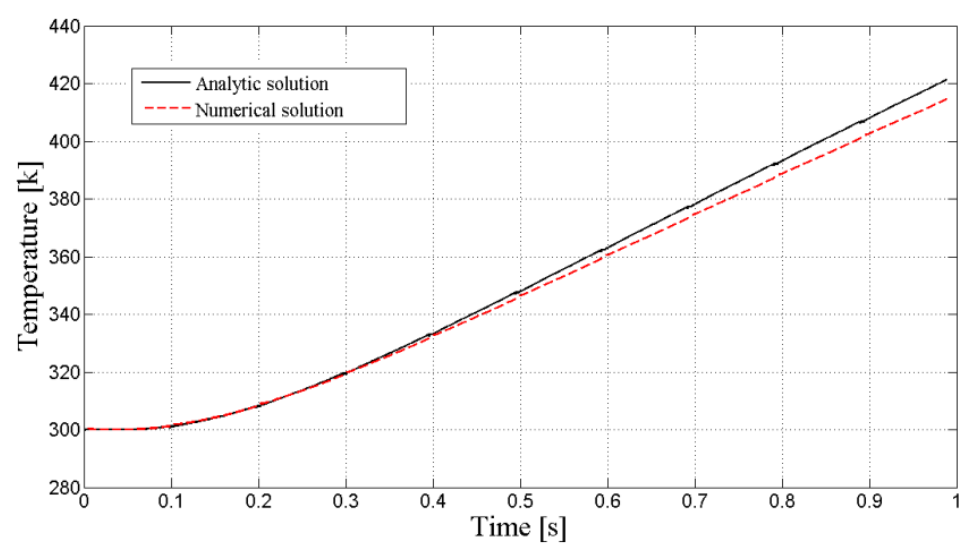

Fig. 11. Temperature time curve for 10 rounds at surface layer for analytical solution and

\subsection{Using ANSYS}

numerical solution

The finite element model of an automatic rifle barrel is constructed in the environment of ANSYS 16 WORKBENCH. Using finite element technique based on Galerking weighted residual or variational approaches, one may cast the above governing couple thermo-elastic differential equations into the finite element form as [20]:

$$
\left[\begin{array}{ll}
{[m]} & {[0]} \\
{[0]} & {[0]}
\end{array}\right]\left\{\begin{array}{l}
\{\ddot{u}\} \\
\{\ddot{T}\}
\end{array}\right\}+\left[\begin{array}{cc}
{[0]} & {[0]} \\
{\left[C^{t u}\right]} & {\left[C^{t}\right]}
\end{array}\right]\left\{\begin{array}{l}
\{\dot{u}\} \\
\{\dot{T}\}
\end{array}\right\}+\left[\begin{array}{cc}
{[K]} & {\left[K^{u t}\right]} \\
{[0]} & {\left[K^{t}\right]}
\end{array}\right]\left\{\begin{array}{l}
\{u\} \\
\{T\}
\end{array}\right\}=\left\{\begin{array}{l}
\{F\} \\
\{Q\}
\end{array}\right\}
$$

Where $\quad \begin{array}{ll}{[m]} & \text { Is the element mass matrix. } \\ \{\mathrm{T}\} & \text { Is the temperature vector. } \\ {[K]} & \text { Is the element stiffness matrix. } \\ \{F\} & \text { Is the element pressure vector. } \\ {\left[C^{t}\right]} & \text { Is the element specific heat matrix. } \\ {\left[K^{u t}\right]} & \text { Is the element thermo-elastic stiffness matrix. } \\ {\left[C^{t u}\right]} & \text { Is the element thermo-elastic damping matrix. } \\ \{Q\} & \text { Is the thermal flux vector. }\end{array}$

The finite element models of the two-layer cylinder subjected to different thermal dynamic loads have been constructed. A coupled-field solid element SOLID226 [20] with capability to perform coupled thermo-elastic analysis has been selected to discrete the domain and obtain the temperature profile through the thickness of the barrel. The element has brick geometry with 20 nodes locating on each corner and middle side of the brick. For structural-thermal analysis, each node has 4 degrees of freedom (DOF) including three translational elastic displacements and temperature. It should be noted that here the transient thermal loads are applied symmetrically in radial direction. Thus, only displacement degrees of freedom in radial direction and temperature will be extracted, as shown in Fig. 12. 


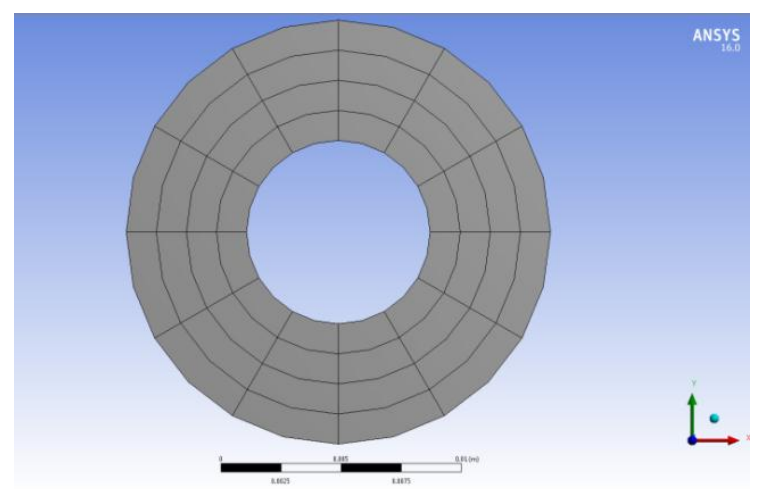

Fig. 12. Finite element model for barrel cylinder

Transient thermal module is used to calculate inner temperature and outer temperature at inner and outer surfaces, respectively for successive 10 rounds, and compared with analytic solution and MATLAB numerical solution. The maximum difference between the two numerical solutions is less than $8 \%$ with respect to analytical solution at point of end of function cycle as shown in Fig. 13 and Fig. 14.

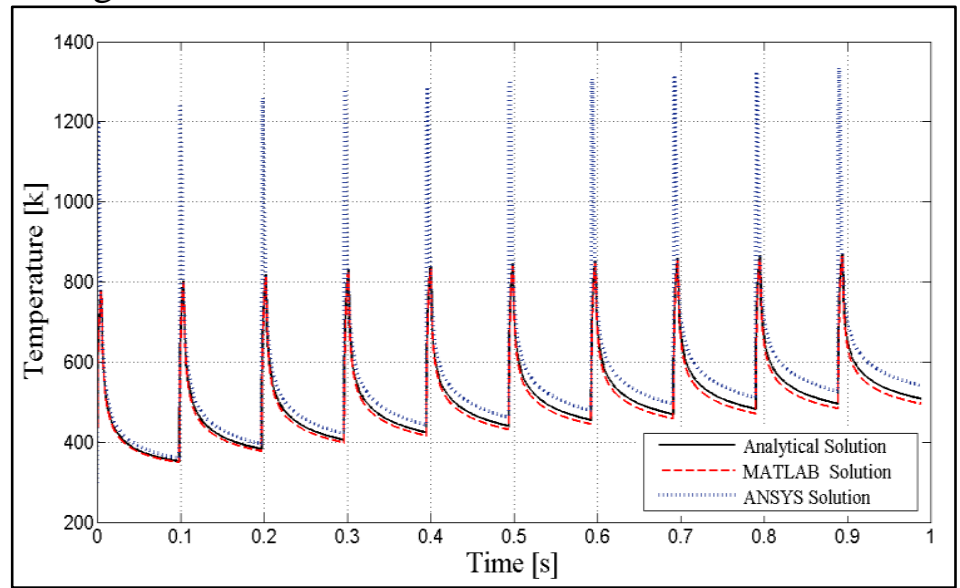

Fig. 13. Temperature time curve for 10 rounds at inner surface for analytical solution and two numerical solutions

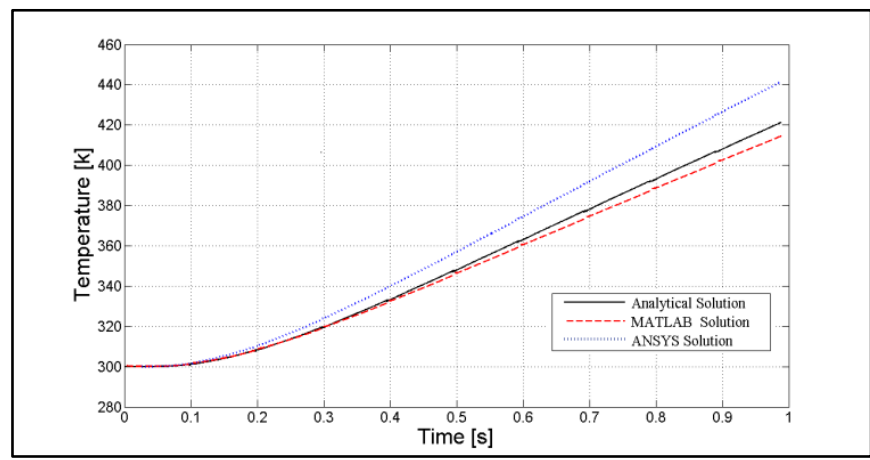

Fig. 14. Temperature time curve for 10 rounds at outer surface for analytical solution and two numerical solutions (has to be changed or start from $300 \mathrm{~K}$ )

To study the effect of relaxation time between bursts, different regime of fire has been used for firing 10 rounds as 3 successive rounds burst then two second relaxation time before the next burst. The analytical solution is compared with another numerical solution by ANSYS as shown in Fig. 15 and Fig. 16 with maximum difference between two solutions is less than $6 \%$ with respect to analytical solution at point of end of function cycle 


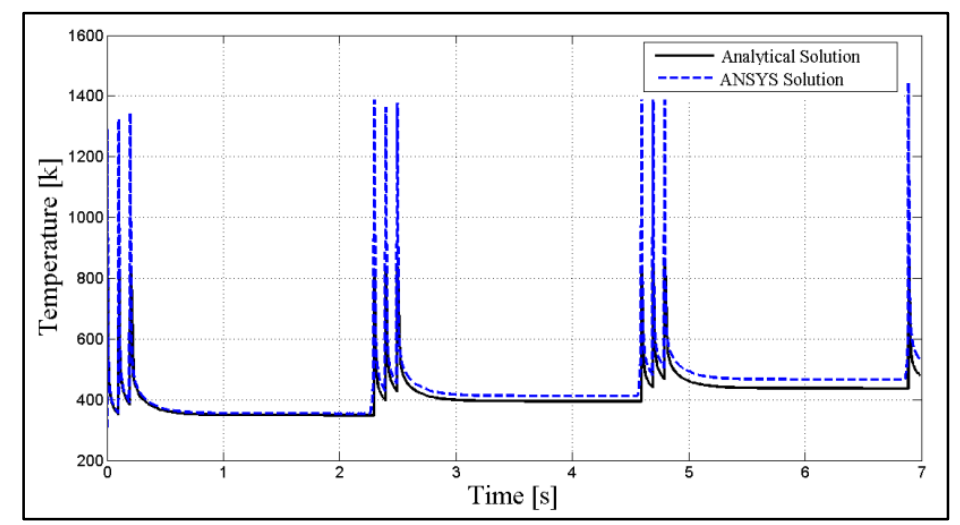

Fig. 15. Temperature time curve for 10 rounds each successive 3 rounds there are 2 [s] rests inner surface for analytical solution and ANSYS numerical solution

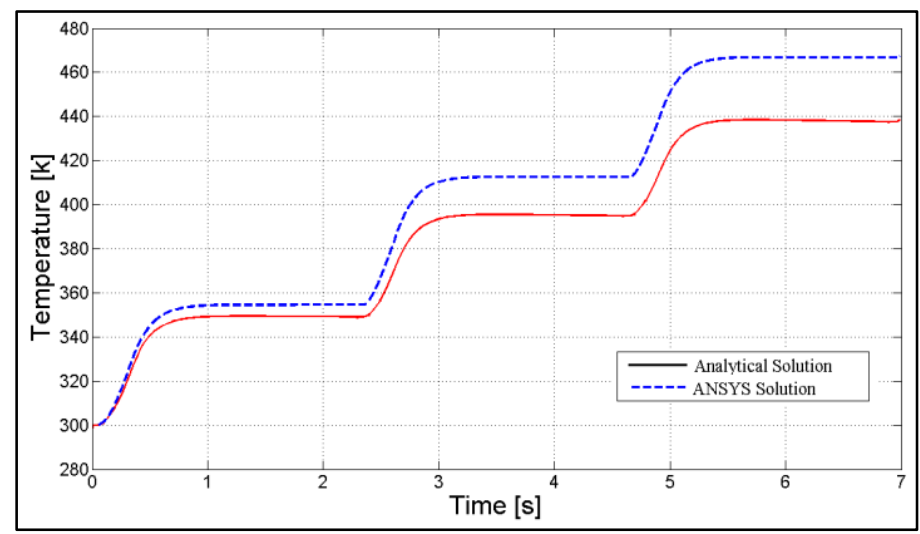

Fig. 16. Temperature time curve for 10 rounds each successive 3 rounds there are 2 [s] rests outer surface for analytical solution and ANSYS numerical solution

(has to be changed or start from $300 \mathrm{~K}$ )

\section{Conclusion}

In this paper, we derive the diffusion equation with time dependent non-homogeneous boundary conditions in one mono-block automatic rifle barrel and verified with numerical solution with same assumptions and also with a F.E.M with real change of the convection coefficients with time.

The temperature difference between the numerical solutions is less than $10 \%$ with respect to the analytic solution at the end of the function cycle especially for the F.E.M. That declares the effect of the using the real time convection coefficients in the finite element model instead of the mean convection coefficient in the other two models.

Also, the relaxation time between bursts has a remarkable effect on the temperature distribution through the wall thickness of the barrel as it reduces the temperature of the inner surface by 5\% and $6 \%$ at the outer surface of the barrel at the end of the function cycle after firing ten rounds. By this method of solution, if an alternative barrel material is desired, the only new input data required for this model would be the thermal properties for that material. Then the barrel temperature trends for various firing schedules can be quickly calculated for the new material to determine if the material would be an effective replacement. Additionally, depending on the strength of the material, there may be a desire to decrease the barrel thickness, which can be done quickly in this model by changing the outer radius. On the other hand, these models can be used to determine the optimum regime of fire for any gun barrel. 


\section{References}

[1] Lawton, B., Thermo-chemical erosion in gun barrels. Wear, 2001. 251(1): p. 827-838.

[2] Qu, P., Q. Li, and S.F. Yang. Temperature Field and Thermal Stress Analysis of Large Caliber Gun Barrel. in Applied Mechanics and Materials. 2014. Trans Tech Publ.

[3] de Swardt, R.R. and T.D. Andrews, Stress Analysis of Autofrettaged Midwall Cooled Compound Gun Tubes. Journal of pressure vessel technology, 2006. 128(2): p. 201-207.

[4] Carslaw, H.S. and J.C. Jaeger, Conduction of heat in solids. Oxford: Clarendon Press, 1959, 2nd ed., 1959.

[5] Carslaw, H. and J. Jaeger. A problem in conduction of heat. in Mathematical Proceedings of the Cambridge Philosophical Society. 1939. Cambridge Univ Press.

[6] O'Neal, D., An analytical solution to transient heat conduction in a composite region with a cylindrical heat source. 1995.

[7] Mulholland, G. and M. Cobble, Diffusion through composite media. International Journal of Heat and Mass Transfer, 1972. 15(1): p. 147-160.

[8] Salt, H., Transient conduction in a two-dimensional composite slab-I. Theoretical development of temperature modes. International journal of heat and mass transfer, 1983. 26(11): p. 1611-1616.

[9] Haji-Sheikh, A. and J. Beck, Temperature solution in multi-dimensional multi-layer bodies. International Journal of Heat and Mass Transfer, 2002. 45(9): p. 1865-1877.

[10] Li, M. and A.C. Lai, New temperature response functions ( $\mathrm{G}$ functions) for pile and borehole ground heat exchangers based on composite-medium line-source theory. Energy, 2012. 38(1): p. 255-263.

[11] Li, M. and A.C. Lai, Analytical model for short-time responses of ground heat exchangers with U-shaped tubes: model development and validation. Applied energy, 2013. 104: p. 510-516.

[12] Mikhailov, M.D. and M.N. Ozisik, Unified analysis and solutions of heat and mass diffusion. 1984.

[13] De Monte, F., An analytic approach to the unsteady heat conduction processes in onedimensional composite media. International Journal of Heat and Mass Transfer, 2002. 45(6): p. 1333-1343.

[14] Jain, P.K. and S. Singh, Analytical solution to transient asymmetric heat conduction in a multilayer annulus. Journal of Heat Transfer, 2009. 131(1): p. 011304.

[15] Singh, S. and P.K. Jain, Finite integral transform method to solve asymmetric heat conduction in a multilayer annulus with time-dependent boundary conditions. Nuclear Engineering and Design, 2011. 241(1): p. 144-154.

[16] J. P. Holman, S.M.U., Heat Transfer Tenth Edition ed.

[17] Robbins, F.W. and T.S. Raab, A Lumped-Parameter Interior Ballistic Computer Code Using the TTCP (The Technical Cooperation Program) Model. 1988, DTIC Document.

[18] Bergman, T.L., et al., Fundamentals of heat and mass transfer. 2011: John Wiley \& Sons.

[19] DAI, A.J.H.-H., HANDBOOK OF MATHEMATICAL FORMULAS AND INTRGRALS.

[20] ANSYS, Theory Manual 2014, Release 16 Documentation, ANSYS Inc 